Check for updates

Cite this: RSC Adv., 2017, 7, 56691

Received 2nd October 2017

Accepted 9th December 2017

DOI: 10.1039/c7ra10893a

rsc.li/rsc-advances

\section{Synthesis of methoxetamine, its metabolites and deuterium labelled analog as analytical standards and their HPLC and chiral capillary electrophoresis separation $\dagger$}

\author{
B. Jurasek, (D) ab M. Himl, ${ }^{c}$ R. Jurok, ${ }^{\text {bc }}$ K. Hajkova, ${ }^{\text {bde }}$ A. Vobinuskova, ${ }^{d}$ P. Rezanka ${ }^{d}$ \\ and M. Kuchar*abe
}

Methoxetamine, a designer drug marketed as a replacement for the dissociative anaesthetic ketamine, has been associated with significant numbers of hospital related intoxications and deaths in Europe. The fast and user-friendly identification and quantification of methoxetamine and its metabolites is a key factor for successful treatment of intoxication. Therefore, we suggested a convenient preparation method which was used for the synthesis of methoxetamine, seven methoxetamine metabolites and a deuterium labelled derivative as analytical standards. Methoxetamine and normethoxetamine were used as starting materials for the preparation of $\mathrm{O}$-demethylated and $\mathrm{N}$-dealkylated metabolites. The multistep synthesis starts from commercially available compounds and offers good yields. Our prepared analytical standards were used for the confirmation of the suggested structure of methoxetamine metabolites in rat urine by LCMS. Capillary electrophoresis was used for the chiral separation of MXE and its metabolites using $\beta$-cyclodextrin, carboxymethylated $\beta$-cyclodextrin, and sulphated $\beta$-cyclodextrin as chiral selectors at various concentrations. Chiral separation was successful for four analytes. A mixture of MXE and its metabolites was subsequently analyzed under optimal conditions, i.e. when using $15 \mathrm{mmol} \mathrm{L^{-1 }}$ $\beta$-cyclodextrin in $50 \mathrm{mmol} \mathrm{L}^{-1}$ phosphate buffer, $\mathrm{pH}$ 2.5. In this case, chiral separation was achieved for three analytes and all analytes were separated from each other.

\section{Introduction}

According to the annual drug reports published by the European Monitoring Centre for Drugs and Drug Addiction (EMCDDA), a new class of psychoactive substances, known as 'legal highs', 'herbal incense', 'designer drugs' or 'research chemicals' has emerged on the drug market in the last decade. The new psychoactive substances (NPSs) include a wide range of products, from natural plant-originating substances to semisynthetic and synthetic compounds. ${ }^{1,2}$ In recent years, the use of new psychoactive substances has grown dramatically. The

${ }^{a}$ Department of Chemistry of Natural Compounds UCT Prague, Technická 5, Prague, 166 28, Czech Republic. E-mail: kuchara@vscht.cz

${ }^{b}$ Forensic Laboratory of Biologically Active Substances UCT Prague, Technická 5, Prague, 166 28, Czech Republic

'Department of Organic Chemistry UCT Prague, Technická 5, Prague, 166 28, Czech Republic

${ }^{d}$ Department of Analytical Chemistry UCT Prague, Technická 5, Prague, 166 28, Czech Republic

${ }^{e}$ National Institute of Mental Health CZ, Topolová 748, Klecany, 250 67, Czech Republic

$\dagger$ Electronic supplementary information (ESI) available. See DOI: $10.1039 / \mathrm{c} 7 \mathrm{ra} 10893 \mathrm{a}$ growing popularity of these compounds is based on availability and apparent 'legality' since many NPSs are yet to be covered by legislative controls pertaining to narcotic and psychotropic substances. $^{3-5}$ In 2016, 66 NPS were notified to the EU Early Warning System operating under EMCDDA. The total number of monitored substances increased to more than $620 .^{4}$ The NPS market is rapidly growing and its legislative regulation is very difficult. In addition to the large number of NPS notified every year, there is a very limited supply (often complete absence) of analytical standards that are important for research, clinical and forensic practice. EMCDDA divides NPS into several classes. ${ }^{6}$ Dissociative anaesthetics are an interesting, however dangerous, group of NPS. The dissociative anaesthetics include compounds with an aryl moiety connected to the cyclohexylamine (arylcyclohexylamines). Arylcyclohexylamines are represented by ketamine and its analogues (Fig. 1).

Ketamine is a well-known anaesthetic with a good safety profile, which is used particularly in anaesthesia, and as coanalgesics in pain management. Moreover, ketamine is suggested as a novel treatment for major depressive disorder and bipolar depression. ${ }^{7,8}$ On the other hand, ketamine (2), phencyclidine (PCP, 1) and methoxetamine (MXE, 3) have an abuse potential.9-11 While ketamine (2) has been registered for 


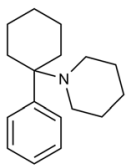

1

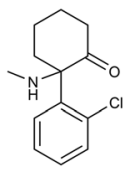

2

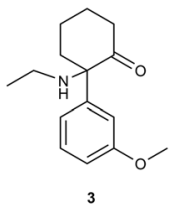

Fig. 1 Phencyclidine (1), ketamine (2), methoxetamine (3).

pharmaceutical usage, many less well characterized arylcyclohexylamines have appeared on the black market as 'research chemicals' and can be obtained from internet retailers. ${ }^{11,12}$

Methoxetamine (3) is a structural analogue of ketamine. MXE was extensively advertised for recreational use as a 'legal' and 'bladder friendly' alternative to ketamine with the main effects of hallucinations, depersonalization and dissociation of the physical body ${ }^{13-16}$ MXE has a sub-micromolar affinity for the glutamate $N$-methyl-D-aspartate (NMDA) receptor $\left(\mathrm{p} K_{\mathrm{i}}=6.59\right)$, which is comparable to that of ketamine ( $\left.K_{\mathrm{i}}=6.18\right)$, and binds to the phencyclidine site on the NMDA receptor. ${ }^{17}$ Very recently, we have published that methoxetamine behaves as a standard dissociative anaesthetic more potent than its analogue ketamine, which in turn might increase the risk of overdose, loss of consciousness and potentially fatal complications. MXE was found to be generally anxiogenic and psychotomimetic, which, in humans is likely to produce unpleasant experiences, and negative psychological sequelae. ${ }^{10}$

Data on the prevalence of use of methoxetamine (3) is limited, but reports of acute intoxications including fatalities have recently appeared. ${ }^{18-20}$ Methoxetamine is associated with 120 non-fatal intoxications and 22 deaths (reported through Early warning system (EWS) by European Member States), however only 55 of these cases have been analytically confirmed. ${ }^{15,21}$ Although many related publications have focused on intoxication with methoxetamine, complete synthesis have not been published yet. Only a brief study of methoxetamine analysis reported the possibility of methoxetamine synthesis analogously to ketamine. ${ }^{22}$

Toxicological detection is necessary as a proof of intoxication or abuse of a certain compound. Urine analysis is one of the most common detection methods in forensic toxicology. Urine samples are usually analysed because of longer detectability, however the knowledge about the metabolism of the investigated compound is often essential, especially, if the substance is completely metabolised and only metabolites are detectable in the urine samples. Furthermore, knowledge about metabolism is a prerequisite for the risk assessment concerning pharmacokinetic interactions caused, e.g. by cytochrome $\mathrm{P} 450$ (CYP) enzymes. The first structures of methoxetamine metabolites have been suggested by Meyer et al. and Menzies et al. ${ }^{23,24}$ They used full-scan GCMS (EI) technique, but this determination has some limitations. Therefore, we synthetized standards of methoxetamine metabolites for the confirmation of their suggested structures and for the pharmacokinetic and metabolism studies. To support the pharmacokinetic and metabolism studies of methoxetamine, stable isotopically labelled standards are an essential tool. Deuterium-labelled internal standards are particularly effective for mass spectrometry analyses and quantification. Many studies have been reported for the preparation of deuterium-labelled controlled drugs as internal standards for the use in GCMS and LCMS analysis. ${ }^{25,26}$

Therefore, our aim was to develop a convenient method for the synthesis of methoxetamine, its metabolites and deuteriumlabelled derivative as analytical standards. All prepared high purity compounds were used for pharmacokinetics. ${ }^{10,27}$

Chiral analysis of drugs and their metabolites can provide very useful information about metabolic pathways in living organisms because it can be expected that metabolic pathways can be different for each enantiomer. Thus enantiomers may have different pharmacological effects. For this reason we used capillary electrophoresis (CE) as chiral separation method for enantioseparation of MXE and its metabolites using cyclodextrin and their derivatives as chiral additives to the background electrolyte (BGE).

\section{Results and discussion}

\section{Synthesis of methoxetamine and its metabolites}

The synthetic route to obtain $N$-dealkylated methoxetamine metabolites is outlined in Fig. 2. Following the synthetic route, treating commercially available 3-methoxybromobenzene (4) with cyclohexanone and activated magnesium under the Grignard protocol afforded intermediate $5{ }^{28}$ which under acidic conditions eliminated water to cyclohexene intermediate $6^{29}$ in high yield $90 \%$. Following epoxidation underwent smoothly in biphases system $\mathrm{CH}_{2} \mathrm{Cl}_{2} / \mathrm{H}_{2} \mathrm{O}$ without phase transfer catalyst to obtain the epoxide $7 .^{30}$ Regioselective opening of the epoxide with $\mathrm{HBr}(\mathrm{aq})$ gave unstable bromohydrine, which was directly oxidized with Jones reagent to afford compound 8 in $64 \%$ overall yield. Nucleophilic substitution of 8 with $\mathrm{NaN}_{3}$ was

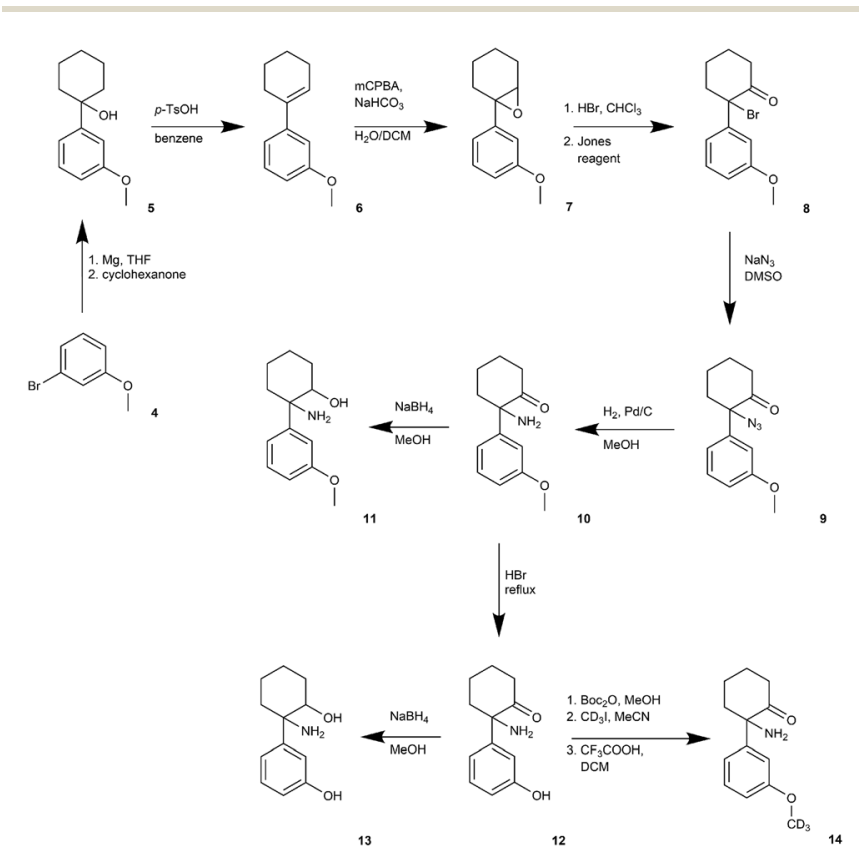

Fig. 2 Synthesis of $N$-dealkylated metabolites 10, 11, 13 and deuterium labelled metabolite 14 . 
followed by almost quantitative azide $\mathbf{9}$ reduction using catalytic hydrogenation. The metabolite normethoxetamine $\mathbf{1 0}$ was treated with $\mathrm{NaBH}_{4}$ affording dihydro-normethoxetamine 11 in average yield $65 \%$. The synthesis of metabolite dihydro-Odesmethyl-normethoxetamine $\mathbf{1 3}$ started from normethoxetamine 10 through intermediate $O$-desmethyl-normethoxetamine 12 obtained by methoxy group cleavage with $\mathrm{HBr}(\mathrm{aq})$ reflux followed by reduction with $\mathrm{NaBH}_{4}$ in high $85 \%$ overall yield. $O$ Desmethyl-normethoxetamine (12) was selectively protected with di-tert-butyldicarbonate and then methylated with $\mathrm{CD}_{3} \mathrm{I}$. Final acid-promoted deprotection provided deuterium labelled metabolite 14.

A synthetic route for the preparation of $O$-demethylated metabolites (Fig. 3) was led through the parent compound methoxetamine (3). We followed the methoxetamine synthesis described by Hays. ${ }^{22}$ Briefly, 3-methoxybenzonitrile 15 underwent Grignard reaction to form 3-methoxyphenyl cyclopentyl ketone $\left(\mathbf{1 6}^{\mathbf{3 1}}\right)$. Further bromination led to alpha-bromo ketone $17,{ }^{32}$ which was treated with ethylamine to form Schiff's base and final heating provided methoxetamine (3). ${ }^{22}$ Metabolite dihydro-O-desmethyl-methoxetamine (21) was obtained by methoxy group cleavage with $\mathrm{HBr}(\mathrm{aq})$ under reflux followed by reduction with $\mathrm{NaBH}_{4}$ in high overall yield (65\%). Direct reduction of methoxetamine with $\mathrm{NaBH}_{4}$ afforded dihydromethoxetamine metabolite 19 in high yield (96\%).

\section{LC-MS/MS analysis of prepared standards}

A sample preparation technique with an LC-MS/MS detection method using synthesized standards was developed and extensively evaluated before it was used for the real samples of pharmacokinetic study. Full description of this method and collected data is shown in our previous work..$^{10,27}$

The aim of the chromatography was to separate compounds with similar $\mathrm{m} / \mathrm{z}$ so that there was no misidentification because of isobar occurrence. There were just two co-elutions within the

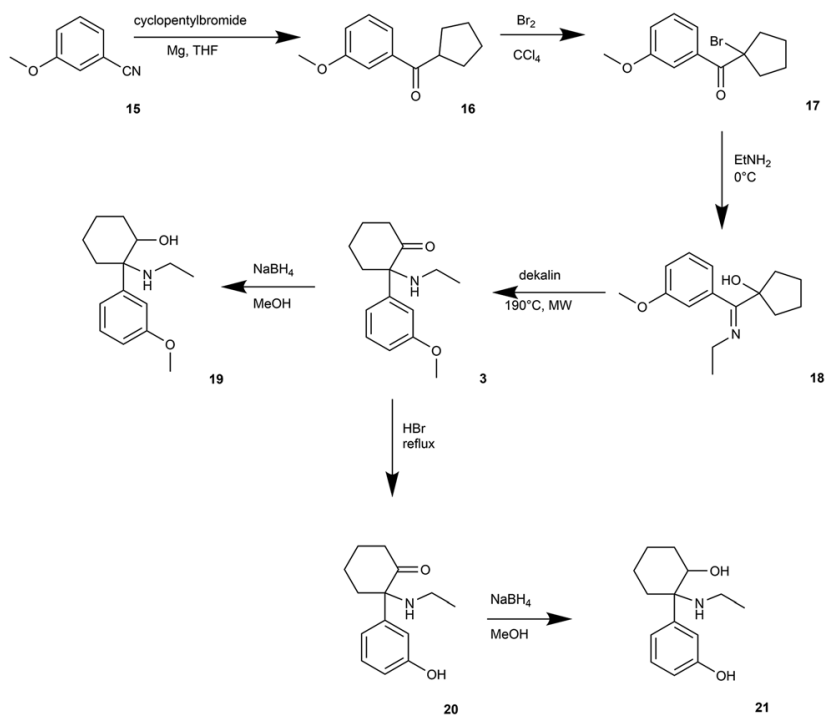

Fig. 3 Synthesis of methoxetamine (3) and $N$-demethylated metabolites 19, 20, 21. analysis; the first one was the common co-elution of $\mathbf{1 0}$ and its deuterium-labelled analog $\mathbf{1 4}$ and the second one was caused by similar retention of 3 and 11, which differ in $\mathrm{m} / \mathrm{z}$. The first stage of separation was accomplished successfully and the second stage was to create sensitive multiple reaction monitoring method (MRM) for MS/MS acquisition. Source conditions and mass transitions were optimized for each analyte. Mixtures of analyzed compounds were measured and evaluated on different concentration levels, and subsequently several different matrices were used (listed in Fig. 4.). ${ }^{10,27}$

However, chiral separation of the analytes was not pursued in the aforementioned publications. In addition, there is no information on the metabolic pathways for particular enantiomers. Thus, it is important to develop not only chromatographic separation method, but, in particular, a method that can be used to differentiate between the enantiomers of a particular drug or its metabolite.

\section{CE analysis of prepared standards}

Our CE study dealt with a suitable chiral selector, its concentration, and $\mathrm{pH}$ of BGE for the enantiomers separations of studied MXE and its metabolites. Three selected cyclodextrins

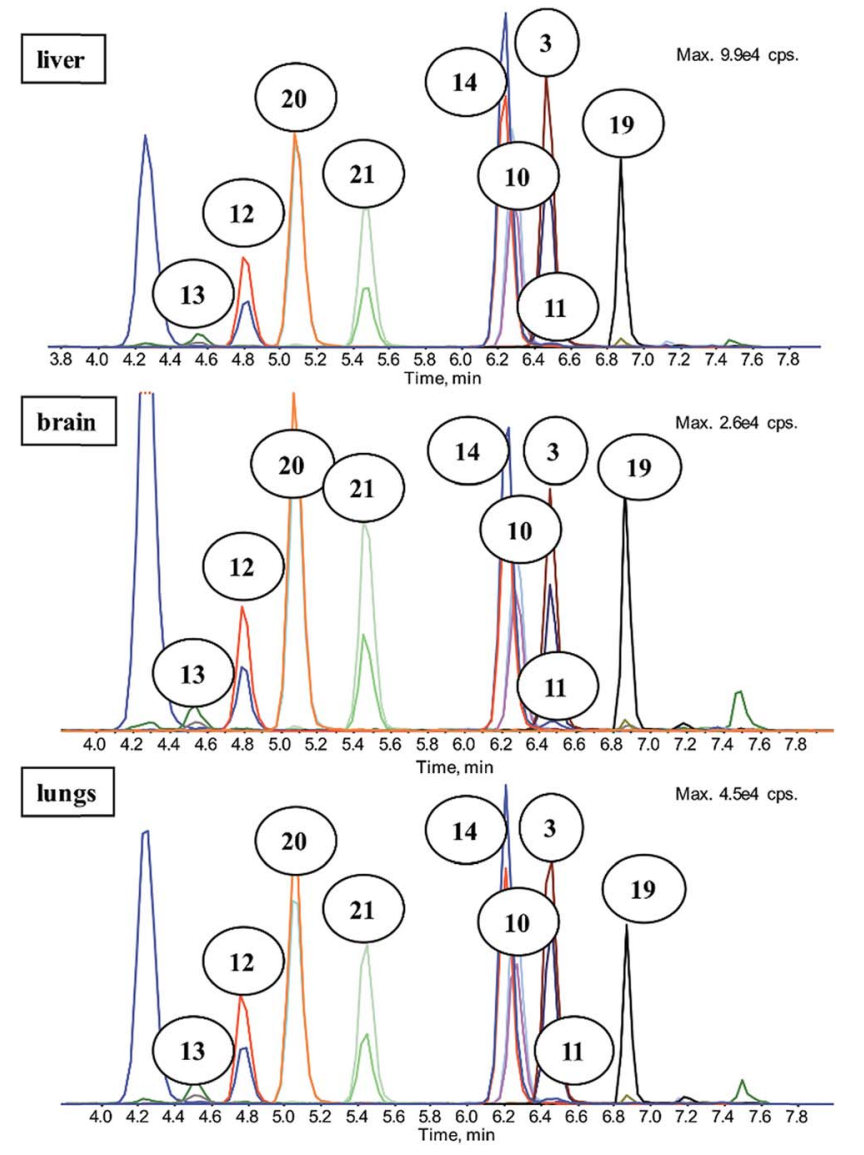

Fig. 4 Chromatograms of matrix-matched calibration on $50 \mathrm{ng} \mathrm{mL}^{-1}$

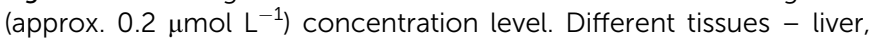
brain, and lung - were enriched by standard compounds and prepared in the same way as the real samples. 
were tested at all above mentioned conditions, i.e. at 4 different concentration levels and 6 different $\mathrm{pH}$. For $\beta$-cyclodextrin (BCD) that is often used due to low cost, its chiral separation was achieved for compound $3(R=0.8)$ and metabolites $\mathbf{1 1}(R=$ $0.6)$ and $20(R=1.1)$. The second tested cyclodextrin was carboxymethylated $\beta$-cyclodextrin (CMBCD) that is often used for separation of compounds containing basic nitrogen group. In this case, compound 3 was partially enantioseparated $(R=1.0)$ and metabolites 10, 11, and 20 were fully enantioseparated $(R>$ 1.5) (Fig. 5). Using sulphated $\beta$-cyclodextrin (SBCD) did not lead to the better resolution, although the same previously mentioned four compounds were also at least partially separated $(0.5<R<1.5)$. To our best knowledge, we achieved enantioseparations of these compounds by CE for the first time.

Because in the living organisms above-mentioned compounds will occur simultaneously, the second part of our CE study focused on the separation of mixtures of MXE and its metabolites. The measurement was carried out under optimal conditions that were chosen from experiments at abovementioned conditions, i.e. 3 types of cyclodextrins, 4 different concentration levels and 6 different $\mathrm{pH}$. The optimal BGE consists of $50 \mathrm{mmol} \mathrm{L}^{-1}$ phosphate buffer ( $\mathrm{pH}$ 2.5) with $15 \mathrm{mmol} \mathrm{L}^{-1} \mathrm{BCD}$ as a chiral additive.

To identify individual signals in the electropherogram as depicted in Fig. 6, new mixtures were prepared with various concentrations of studied chiral compounds. These mixtures were analysed under the identical conditions as the original mixture and the assignment of the signals was carried out using the peak areas and UV-vis spectra of individual analysed
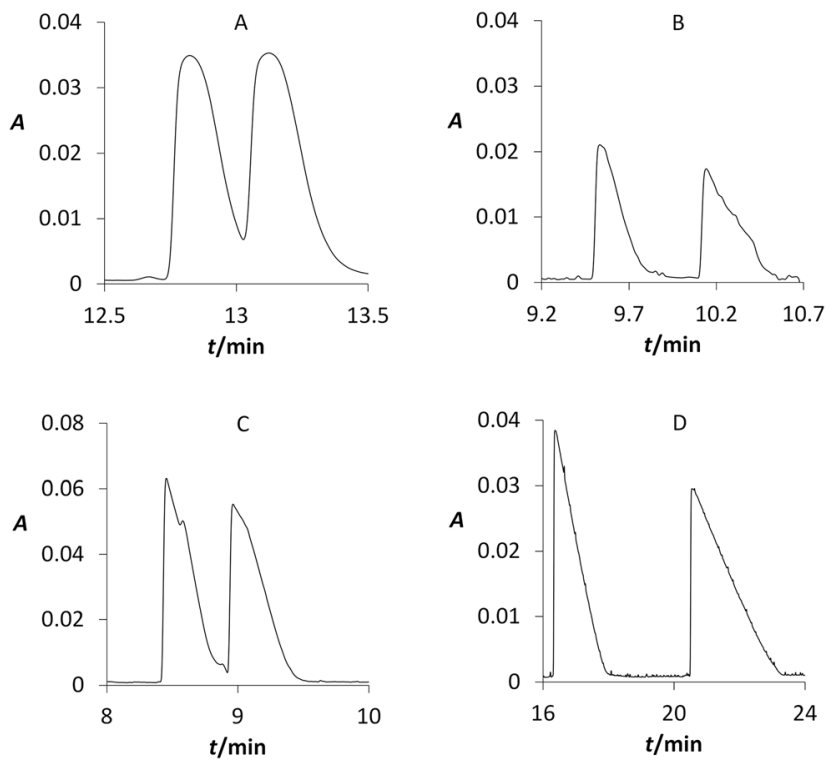

Fig. 5 Electropherograms of analyzed compounds; dependences of absorbance at $207 \mathrm{~nm}$ on electromigration time. Separated analytes (BGE): (A) 3 (10 mmol L ${ }^{-1}$ CMBCD, $50 \mathrm{mmol} \mathrm{L}^{-1}$ phosphate buffer, $\mathrm{pH}$ 2.5); (B) 10 (10 mmol L ${ }^{-1}$ CMBCD, $50 \mathrm{mmol} \mathrm{L}^{-1}$ formic buffer, $\mathrm{pH} 4.0$ ); (C) 11 (10 mmol L-1 CMBCD, $50 \mathrm{mmol} \mathrm{L}^{-1}$ acetic buffer, pH 5.0); (D) 20 (7 mmol L ${ }^{-1}$ CMBCD, 50 mmol L ${ }^{-1}$ formic buffer, $\mathrm{pH} 4.0$ ); fused-silica capillary: od/id $=375 / 75 \mu \mathrm{m}$, total/effective length $58.5 / 50.0 \mathrm{~cm}$; voltage $20 \mathrm{kV}$; temperature $25^{\circ} \mathrm{C}$.

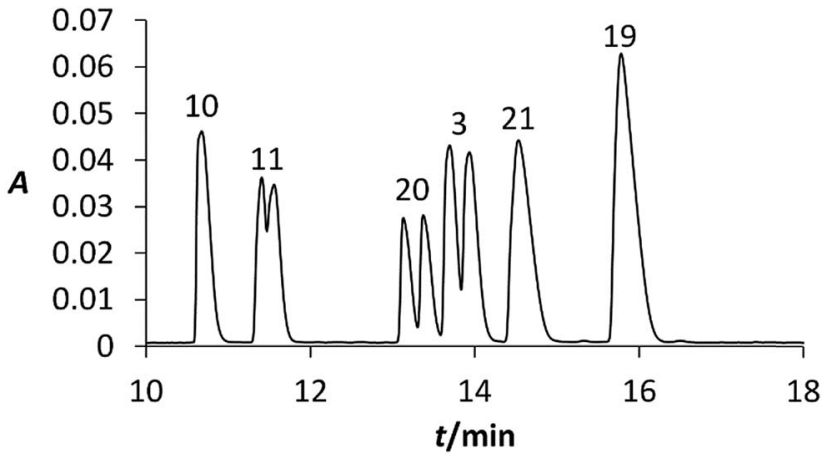

Fig. 6 Electropherogram of analyzed mixture of MXE and its metabolites; dependences of absorbance at $207 \mathrm{~nm}$ on electromigration time; BGE: $15 \mathrm{mmol} \mathrm{L}^{-1} \mathrm{BCD}, 50 \mathrm{mmol} \mathrm{L}^{-1}$ sodium phosphate, $\mathrm{pH}$ 2.5; fused-silica capillary: od/id $=375 / 75 \mu \mathrm{m}$, total/effective length $58.5 / 50.0 \mathrm{~cm}$; voltage $20 \mathrm{kV}$; temperature $25^{\circ} \mathrm{C}$.

compound. As can be seen in Fig. 6, six analytes were separated from each other and the half of them was partially enantioseparated.

\section{Conclusions}

In conclusion, we established an efficient synthetic route towards normethoxetamine- $d_{3}(\mathbf{1 4})$ and seven methoxetamine metabolites, namely, dihydro-O-desmethyl-normethoxetamine (13), O-desmethyl-normethoxetamine (12), O-desmethylmethoxetamine (20), dihydro-O-desmethylmethoxetamine (21), normethoxetamine (10), dihydro-normethoxetamine (11), dihydromethoxetamine (19).

A sample preparation technique with LC-MS/MS method using synthesized standards was developed and extensively evaluated before it was used on the real samples of pharmacokinetic study. Mixtures of analyzed compounds were measured and evaluated on different concentration levels, and subsequently several different matrices were also used. Full description of this method and collected data is shown in our previous work. ${ }^{10,27}$

We studied the influence of the type and concentration of CDs on the enantioselectivity of methoxetamine and its derivatives by chiral CE. The results of the analyses (carried out in $50 \mathrm{mmol} \mathrm{L}^{-1}$ buffer at pH 2.5 to 5.0 with the addition of 4 to $15 \mathrm{mmol} \mathrm{L}^{-1} \mathrm{BCD}$, CMBCD or SBCD) demonstrate a significant dependence of enantioseparations on the conditions studied. Four compounds (3, 10, 11, and 20) were successfully enantioseparated.

\section{Experimental section}

Chemicals and materials

Hydrochloric acid (30\%) (Suprapur, Merck, Germany), $1 \mathrm{~mol} \mathrm{~L}^{-1}$ sodium hydroxide (Tripur, Merck), ortho-phosphoric acid (50\%), $\beta$-cyclodextrin (BCD), carboxymethylated $\beta$-cyclodextrin (CMBCD) and sulphated $\beta$-cyclodextrin (SBCD) (all Sigma-Aldrich, Czech Republic). Diethyl ether solution of hydrochloride was prepared from commercial diethyl ether, 
commercial concentrated hydrochloric acid and calcium chloride as drying agents. Solvents were acquired from commercial sources and were used after distillation. Other commercial reagents were used without further purification. The reactions were monitored with the aid of thin-layer chromatography (TLC Silica gel 60 F254) and pre-coated reverse phase gel plates (TLC RP-18 F254). Visualization was carried out with UV light. Chromatography refers to flash column chromatography and it was carried out with the indicated solvents on silica gel (particle size $0.040-0.060 \mathrm{~mm}$ ) or reverse phase column (Redisep RF Gold C18). All operations involving air-sensitive reagents were performed under an inert atmosphere of dry argon using syringe and cannula techniques, oven-dried glassware, and freshly distilled and dried solvents. Thermal rearrangement were carried out in Microwave reactor (Biotage Initiator Classic) melting points were determined using a melting point apparatus (PGH Rundfunk-Fernsehen), and they are uncorrected. NMR spectra were recorded in $\mathrm{CDCl}_{3}$ or $\mathrm{CD}_{3} \mathrm{OD}$ at room temperature on a Varian Gemini $300 \mathrm{MHz}\left({ }^{1} \mathrm{H}\right.$ NMR $300 \mathrm{MHz},{ }^{13} \mathrm{C}$ NMR $75 \mathrm{MHz})$ or an Agilent $400 \mathrm{MR}$ DDR2 $\left({ }^{1} \mathrm{H}\right.$ NMR $400 \mathrm{MHz},{ }^{13} \mathrm{C}$ NMR $100 \mathrm{MHz}$ ). The spectra were referenced to residual solvent protons in the ${ }^{1} \mathrm{H}$ NMR spectra $(7.26 \mathrm{ppm}$ for $\mathrm{CDCl}_{3}$ and 4.84 and $3.31 \mathrm{ppm}$ for $\mathrm{CD}_{3} \mathrm{OD}$ ) and to solvent carbons in the ${ }^{13} \mathrm{C}$ NMR spectra $\left(77.0 \mathrm{ppm}\right.$ for $\mathrm{CDCl}_{3}$ and $49.05 \mathrm{ppm}$ for $\mathrm{CD}_{3} \mathrm{OD}$ ). Infrared (IR) spectra were measured on FTIR Nicolet 6700 (Thermo-Nicolet) coupled with ATR cell GladiATR (Pike). High-resolution MS (HRMS) were run either by the ESI ionization or atmospheric pressure chemical ionization (APCI) mode. High resolution mass spectra (HRMS) were recorded using a Thermo Scientific LTQ Orbitrap Velos.

CE separations were performed with an Agilent CE instrument (Agilent 3D HPCE, Germany) equipped with UV-vis diodearray detector. Bare fused silica capillary of $375 / 75 \mu \mathrm{m}$ od/id and $58.5 / 50 \mathrm{~cm}$ total/effective length obtained from Polymicro Technologies (AZ, USA) was used.

\section{LC conditions}

LC-MS/MS was performed using an Agilent 1200 HPLC series (Agilent Technologies, Germany) in tandem with API 3200 MS system (AB Sciex, Canada). ZORBAX Eclipse Plus C18 $(50 \times 2.1$ $\mathrm{mm}, 5 \mu \mathrm{m})$ with a pre-column was used for the chromatographic separation with a gradient of $0.1 \%(\mathrm{v} / \mathrm{v})$ formic acid in deionized water (mobile phase A) and $0.1 \%(\mathrm{v} / \mathrm{v})$ formic acid in methanol (mobile phase B) at flow rate of $250 \mu \mathrm{L} \mathrm{min}{ }^{-1}$. The gradient set-up was: $0-4 \mathrm{~min}$ from $90 \% \mathrm{~A}$ to $60 \% \mathrm{~A} ; 4-$ 5 min to $0 \% \mathrm{~A} ; 5-5.5 \mathrm{~min}$ at $0 \% \mathrm{~A} ; 5.5-5.7 \mathrm{~min}$ back to $90 \% \mathrm{~A}$, and equilibration at the same level to $10 \mathrm{~min}$. The valve arrangement was: 3.1-7.6 min to the MS source. The MS conditions were following: electrospray ionization (ESI) in positive mode, ionization voltage of $5500 \mathrm{~V}$, source temperature of $500{ }^{\circ} \mathrm{C}$ and gas flow rates-curtain gas 15, GS1 and GS2 50 arbitrary units. Data were acquired in multiple reaction monitoring mode (MRM) using Analyst 1.4.2 (AB Sciex, Canada). ${ }^{27}$

\section{CE conditions}

Individual analyzed compounds were dissolved in water at $10 \mathrm{mmol} \mathrm{L}^{-1}$ concentration. For the CE experiments the analyte solutions were further diluted with water to the final concentration $1 \mathrm{mmol} \mathrm{L}^{-1}$. For the determination of migration order of particular compounds the mixture composed of analyzed compounds at different concentration was used. The background electrolyte consisted of $50 \mathrm{mmol} \mathrm{L}^{-1}$ buffers at $\mathrm{pH} 2.5$, $3.0\left(50 \mathrm{mmol} \mathrm{L}^{-1}\right.$ orthophosphoric acid adjusted to appropriate pH with $\left.1 \mathrm{~mol} \mathrm{~L}^{-1} \mathrm{NaOH}\right), 3.5,4.0\left(50 \mathrm{mmol} \mathrm{L}^{-1}\right.$ formic acid adjusted to appropriate $\mathrm{pH}$ with $\left.1 \mathrm{~mol} \mathrm{~L}^{-1} \mathrm{NaOH}\right), 4.5,5.0$ $\left(50 \mathrm{mmol} \mathrm{L}{ }^{-1}\right.$ acetic acid adjusted to appropriate $\mathrm{pH}$ with $1 \mathrm{~mol} \mathrm{~L}^{-1} \mathrm{NaOH}$ ), and various concentrations of the studied CDs $\left(4,7,10,15 \mathrm{mmol} \mathrm{L}^{-1}\right.$ for BCD, CMBCD, and SBCD). A new fused silica capillary was first rinsed with $1 \mathrm{~mol} \mathrm{~L}^{-1} \mathrm{NaOH}$ for $30 \mathrm{~min}$, then with $\mathrm{H}_{2} \mathrm{O}$ for $30 \mathrm{~min}$. Between the runs the capillary was rinsed at $99.4 \mathrm{kPa}$ first with $0.1 \mathrm{~mol} \mathrm{~L}^{-1} \mathrm{NaOH}$ for 2 min then with $\mathrm{H}_{2} \mathrm{O}$ also for $2 \mathrm{~min}$, and finally with running buffer again for 2 min (for the capillary washing a different buffer solution than for the subsequent analysis was used). The analytes were injected hydrodynamically by pressure of $1.5 \mathrm{kPa}$ for $5 \mathrm{~s}$. All the separations were performed at $20 \mathrm{kV}$ (anode at the injection capillary end) with a voltage ramp time of $12 \mathrm{~s}$. Detection was carried out at $207 \mathrm{~nm}$ and the capillary was thermostated at $25{ }^{\circ} \mathrm{C}$ during the analyses.

\section{Conflicts of interest}

There are no conflicts to declare.

\section{Acknowledgements}

This study was funded by a specific university research (project MSMT No. 20-SVV/2017) and by the Ministry of Interior of the Czech Republic (project VG20172020056).

\section{Notes and references}

1 European Monitoring Centre for Drugs and Drug Addiction and Europol, EU drug markets report - a strategic analysis, Portugal and Haag, 2013.

2 UNODC Early warning advisory on new psychoactive substances, What are NPS?, https://www.unodc.org/LSS/ Page/NPS, accessed 1 January 2017.

3 L. Hondebrink, J. J. Nugteren-van Lonkhuyzen, D. Van Der Gouwe and T. M. Brunt, Drug Alcohol Depend., 2015, 147, 109-115.

4 European Monitoring Centre for Drugs and Drug Addiction and Europol, European Drug Report 2017: Trends and Developments, Luxembourg, 2017.

5 European Monitoring Centre for Drugs and Drug Addiction, European Drug Report 2016, Luxembourg, 2016.

6 European Monitoring Centre for Drugs and Drug Addiction and Europol, EU drug markets report: In-depth analysis, Luxembourg, 2016. 
7 E. E. Lee, M. P. Della Selva, A. Liu and S. Himelhoch, Gen. Hosp. Psychiatr., 2015, 37, 178-184.

8 S. Sassano-Higgins, D. Baron, G. Juarez, N. Esmaili and M. Gold, Depression Anxiety, 2016, 33, 718-727.

9 C. J. Botanas, J. B. de la Peña, I. J. dela Peña, R. Tampus, R. Yoon, H. J. Kim, Y. S. Lee, C. G. Jang and J. H. Cheong, Pharmacol., Biochem. Behav., 2015, 133, 31-36.

10 R. R. Horsley, E. Lhotkova, K. Hajkova, B. Jurasek, M. Kuchar and T. Palenicek, Brain Res. Bull., 2016, 126, 102-110.

11 J. B. Zawilska, Toxicol. Lett., 2014, 230, 402-407.

12 H. Morris and J. Wallach, Drug Test. Anal., 2014, 6, 614-632.

13 C. Ornella, S. Fabrizio, S. Pierluigi, F. Susanne, A. Sulaf, S. Jacqueline, C. John and T. Giuseppina, Hum. Psychopharmacol., 2012, 27, 145-149.

14 P. I. Dargan, H. C. Tang, W. Liang, D. M. Wood and D. T. Yew, Clin. Toxicol., 2014, 52, 176-180.

15 European Monitoring Centre for Drugs and Drug Addiction, Methoxetamine - Report on the risk assessment of 2-(3methoxyphenyl)-2-(ethylamino)cyclohexanone (methoxetamine) in the framework of the Council Decision on new psychoactive substances, Luxembourg, 2014.

16 B. Jurásek and M. Kuchař, Drugs \& Forensics Bulletin, 2016, 1, 27-31.

17 B. L. Roth, S. Gibbons, W. Arunotayanun, X.-P. Huang, V. Setola, R. Treble and L. Iversen, PLoS One, 2013, 8, 1-5.

18 K. E. Hofer, B. Grager, D. M. Müller, C. Rauber-Lüthy, H. Kupferschmidt, K. M. Rentsch, A. Ceschi, D. M. Muller, C. Rauber-Luthy, H. Kupferschmidt, K. M. Rentsch and A. Ceschi, Ann. Emerg. Med., 2012, 60, 97-99.

19 D. M. Wood, S. Davies, M. Puchnarewicz, A. Johnston and P. I. Dargan, Eur. J. Clin. Pharmacol., 2012, 68, 853-856.

20 M. Wikstrom, G. Thelander, M. Dahlgren and R. Kronstrand, J. Anal. Toxicol., 2013, 37, 43-46.
21 M. T. Zanda, P. Fadda, C. Chiamulera, W. Fratta and L. Fattore, Behav. Pharmacol., 2016, 27, 489-496.

22 P. A. Hays, J. F. Casale and A. L. Berrier, Microgram J., 2012, 9, 3-17.

23 M. R. Meyer, M. Bach, J. Welter, M. Bovens, A. Turcant and H. H. Maurer, Anal. Bioanal. Chem., 2013, 405, 6307-6321.

24 E. L. Menzies, S. C. Hudson, P. I. Dargan, M. C. Parkin, D. M. Wood and A. T. Kicman, Drug Test. Anal., 2014, 6, 506-515.

25 R. S. Sulake, C. Chen, H.-R. Lin and A.-C. Lua, Bioorg. Med. Chem. Lett., 2011, 21, 5719-5721.

26 A. L. Patton, K. A. Seely, S. Pulla, N. J. Rusch, C. L. Moran, W. E. Fantegrossi, L. D. Knight, J. M. Marraffa, P. D. Kennedy, L. P. James, G. W. Endres and J. H. Moran, Anal. Chem., 2014, 86, 1760-1766.

27 K. Hajkova, B. Jurasek, D. Sykora, T. Palenicek, P. Miksatkova and M. Kuchar, Anal. Bioanal. Chem., 2016, 408, 1171-1181.

28 J. Wallach, G. De Paoli, A. Adejare and S. D. Brandt, Drug Test. Anal., 2014, 6, 633-650.

29 D. Huang, H. Wang, F. Xue and Y. Shi, J. Org. Chem., 2011, 76, 7269-7274.

30 A. C. White and G. Bradley, US Pat., US4387097 A1, 1983.

31 X. Cheng, R. Goddard, G. Buth and B. List, Angew. Chem., Int. Ed., 2008, 47, 5079-5081.

32 E. Benchikh, P. Fitzgerald, P. Lowry and I. McConnell, US Pat., US2017/3308, 2017.

33 T. Korenaga, A. Ko, K. Uotani, Y. Tanaka and T. Sakai, Angew. Chem., Int. Ed., 2011, 50, 10703-10707.

34 L. Ackermann, A. R. Kapdi, S. Fenner, C. Kornhaaß and C. Schulzke, Chem.-Eur. J., 2011, 17, 2965-2971.

35 C. H. Senanayake, T. P. Jerussi, P. T. Grover, Q. K. Fang and C. Mark, US Pat., US2003/0171440A1, 2003.

36 C. Stevens and D. Parke, US Pat., US3254124, 1966. 